\title{
APPLYING THE CRITERIA OF UlRICH AND BROCKBANK FOR THE ASSESSMENT OF THE ROLE OF HUMAN RESOURCES AS A STRATEGIC BUSINESS PARTNER IN A MINING COMPANY
}

Authors:

Lize de Bruyn ${ }^{1}$

Gerhard (Gert) Roodt

\section{Affiliations:}

${ }^{1}$ Department of Industrial Psychology and People Management, University of Johannesburg, South Africa

Correspondence to: Gerhard (Gert) Roodt

e-mail:

groodt@uj.ac.za

\section{Postal address:}

PO Box 524, Auckland

Park, 2006, South Africa

\section{Keywords:}

human-resource

management; strategic

human-resource

management; strategic business partner; Ulrich's and Brockbank's criteria; qualitative evaluation

\section{Dates:}

Received: 05 Mar. 2009

Accepted: 31 July 2009

Published: 07 Oct. 2009

How to cite this article: De Bruyn, L., \& Roodt, G. (2009). Applying the criteria of Ulrich and Brockbank for the assessment of the role of human resources as a strategic business partner in a mining company. $S A$ Journal of Human Resource Management/SA Tydskrif vir Menslikehulpbronbestuur 7(1), Art. \#200, 11 pages. DOI: 10.4102/sajhrm.v7i1.200

This article is available at:

http://www.sajhrm.co.za

(C) 2009. The Authors. Licensee: OpenJournals Publishing. This work is licensed under the Creative Commons Attribution License

\begin{abstract}
The aim of this study was to apply the 14 criteria of Ulrich and Brockbank for the assessment of the movement of a human-resource function from its current development phase to a strategic business-partner role. A qualitative method, based on casing, was adopted as the research strategy. Data were collected from members of the human-resource forum of an organisation through a semi-structured focus group, individual interviews and solicited document reviews. The collected data were analysed through open coding or thematic analyses. Findings indicated that the organisation's human-resource function was moving from operational human-resource service provision to a more strategic focus.
\end{abstract}

\section{Core focus of the study}

\section{INTRODUCTION}

Authors have argued in articles, books and studies that the human resources (HR) function should become a strategic business partner, but are HR functions really achieving this? What does becoming a strategic business partner entail (Lawler \& Mohrman, 2003)? This study endeavoured to find answers to these complex questions.

\section{Context of the study}

The HR function has transitioned through different phases, from playing a purely administrative role to a service-delivery role to a strategic-partner role. Focus is currently shifting towards human-capital management. The HR function can and is increasingly making significant contributions to the building of an organisation that is staffed by effective human capital to carry out the work of the organisation and enable the accomplishment of business strategy (Lawler \& Mohrman, 2003). This is also referred to as 'talentship' (Boudreau \& Ramstad, 2007).

Strategic human-resource management (HRM) is a complex process that is constantly evolving and being studied and discussed by academics and commentators. Important questions are raised on the management of human capital, the kind of functions to be performed by HR with respect to human capital management and the organisation of the HR function for the addition of value in the changing business environment (Lawler \& Mohrman, 2003). It is thus imperative that the HR function first focusses more on strategic issues and then on demonstrating its direct impact on business outcomes through proper measurement.

Sullivan $(2005$, p. 148) stated that 'most C-level executives have come to expect very little from their HR departments with regards to impacting the bottom line other than through cost containment'. It is believed, however, that HR has the highest potential impact on both corporate results and the bottom line. Organisations should therefore demand that their HR shift from its traditional decision-making model based on intuition to one based on data. The question is: How can an organisation ensure that its HR function transforms? According to Sullivan, CEOs should demand change by

- instilling accountability (HR should accept accountability for the measurement of and continual increase in workforce productivity), demanding speed, quality, cost efficiency and improved bottom-line impact

- demanding data-based decision making

- making managers accountable and reward them appropriately for good results.

Hall (2005, p. 102) believed that, in five years, the HR function would look very like any other strategic part of an organisation. He felt that, in future, HR leaders may view their roles as part of the following three components:

- HR leaders should be strategic partners with their business counterparts and be aligned with their respective business units

- HR leaders should leverage centres of expertise to provide baseline programmes for payroll and benefits, for example

- HR should focus even more on talent acquisition and retention. This is where companies could gain true competitive advantage: having the right people in the right job doing the right work.

A possible fourth component that HR leaders may use is the consideration of how their processes may be integrated and supported by even more robust technology for greater efficiency (Hall, 2005).

According to Ulrich (1998), some consensus is emerging on several themes:

- HR is under scrutiny, which is to be welcomed

- HR, as we know it, should change

- A changing HR will represent important challenges and will require new competencies 
- If HR does not meet the challenges of change, it is at risk of being disbanded.

Ulrich (2005) stated that the universal value premise is that value is defined by the receiver more than the giver. This requires HR professionals to focus less on what they do and more on what they deliver. It is therefore imperative that HR professionals understand emerging basic trends for them to have credibility at the strategic table and to support statements with empirical data about these business trends. According to Meisinger (in Cascio \& Boudreau, 2008), many HR professionals are still not competent in the use of measurement to move their business forward.

\section{Rationale for the study}

Kochan and Dyer (1993) reported that the strategic HRM models of the 1980s were too limited and reactive in character because they depended heavily on the values, strategies and support of top executives and line managers. They mentioned that a model capable of achieving sustained and transformational change should incorporate more active roles in respect of other stakeholders.

Sanz-Valle, Sabater-Sanchez and Aragon-Sanchez (1999) examined matches between HR practices and types of business strategies and found significant associations between some HR practices and business strategies in companies.

With these taken into consideration, the value-proposition model by Ulrich and Brockbank (2005) (see the following) provides a framework for the assessment of the HR function's role and a way of building a specific HR strategy. The mode by Ulrich and Brockbank incorporates what can and should exist for all stakeholders, namely (1) a set of standards directing HR investment in strategy, structure and practices, and (2) a template for ensuring that each HR professional contributes towards achieving this.

\section{Literature review}

The value-proposition model by Ulrich and Brockbank (2005) emphasises that HR succeeds when it creates value by meeting the requirements of five elements. The aim of this study was to evaluate the extent to which HR meets the requirements of these five elements, which are set out here.

\section{Knowing external business realities}

Every firm operates in the context of external business realities. The external business realities that currently have the greatest influence on external customers and owners are the radical transformation of technology, economic and regulatory environments, and major changes in human demographics, al in a context of increasing globalisation (Ulrich \& Brockbank, 2005).

Brown (2003) stated that HR departments are not simply trying to improve what they have always done but are also transforming through the re-creation and reinvention of an HR function driven by a business need rather than by an HR-function need. The top driver of transformation is the desire to become a more strategic function and to align HR with the organisation's strategic goals (Brown, 2003). Christensen (2005) supported the view that HR leaders should prove that they deserve to sit at the conference table. He stated that, to accomplish this goal, HR leaders should ensure that they thoroughly understand the business, including the products, sales strategies and customer service. Hagen (1998) and Christensen shared the same view of the HR function being an 'organisational architect' or 'scout' by scanning the landscape and environment and by integrating 'people issues' with corporate business components.

Longbottom (2005) argued that the function is better employed in providing leadership on people matters as a means of delivering competitive advantage. This is where value is added.
According to him, HR is increasingly becoming central to every management decision, reflecting the pivotal role of people in the delivery of business objectives.

\section{Serving internal and external stakeholders}

Value is defined by the receivers of HR work - investors, customers, line managers and employees - more than the givers. HR is successful if and when its stakeholders perceive that it produces value (Ulrich \& Brockbank, 2005) or that it is effective.

According to Boudreau and Ramstad (2007, p. 120), effectiveness describes the relationship between talent and organisational performance and the portfolio of policies and practices that creates and supports that performance. Cantrell (2005) agreed with Ulrich and Brockbank that effectiveness is not measured by inputs but by results. Mayo (2004, p. 7) added to these arguments by recommending that a clear distinction be made between HR's 'functional added value' and the value that people throughout an organisation can add to different stakeholders. Hagen (1998) described the role of HR as that of a chess master engaging in constant evaluation of all 'players' on the 'chess board', determining how best to influence and leverage change champions with the authority to make change happen. Christensen (2005) emphasised that HR should serve line managers in such a way that they do not attempt to resolve any people or organisational matters without advice from and consultation with the HR function.

\section{Crafting HR practices - (people, performance,} information and work processes)

People and performance management are the traditional province of HR but HR professionals should also devote their attention to two additional areas: the flow of information and the flow of work. These emerging HR activity areas have greater impact on the human side of a business and add value to key stakeholders (Meisinger in Cascio \& Boudreau, 2008; Ulrich \& Brockbank, 2005).

The use of metrics in HR is slowly growing but many typical metrics have no causal relationships to desired outcomes. It is proposed that HR executives be given the opportunity to sit at the executive-committee table as strategic partners by adopting new innovative solutions from the marriage of science, technology and intellectual resources (Singh \& Latib, 2005). Although many academic researchers have emphasised the need for measurement and HR metrics (Cantrell, 2005; Higgins, 2005; Mayo, 2004; Singh \& Latib, 2005; Sullivan, 2005), there is still a significant gap between the stated objectives of HR functions and the methods used to measure their performance and valueadd to organisational goals.

Longbottom (2005, p. 15) disagreed with this argument. He claimed that the HR profession has come to a sorry state if it stakes its reputation on such a blunt instrument and the structures of regulatory compliance. He also mentioned that statistical data should not be confused with the key performance indicators that are integral to the management of a business. Longbottom stated that playing the numbers game does not raise the profile or improve the performance of the HR profession; neither does it secure the place of $\mathrm{HR}$ as a strategic business partner to the chief executive.

Huselid, Becker and Beatty (2005) suggested that HR success is about driving workforce success and that HR success should therefore be measured by the impact of HR on workforce success through effective HR practices. Conner and Ulrich (1996) believed that, for HR effectiveness to be improved and for it to have greater impact, the HR function should understand how to add value in an organisation by helping line managers align HR and practices with business needs. 
TABLE 1

Five elements and fourteen criteria by Ulrich and Brockbank of the HR value proposition in becoming a strategic business partner

\begin{tabular}{|c|c|c|}
\hline $\begin{array}{l}\text { PREMISE OF THE HR } \\
\text { VALUE PROPOSITION }\end{array}$ & $\begin{array}{l}\text { ELEMENTS OF THE HR VALUE } \\
\text { PROPOSITION }\end{array}$ & CRITERIA FOR AN EFFECTIVE HR FUNCTION \\
\hline \multirow{14}{*}{$\begin{array}{l}\text { HR succeeds when it } \\
\text { creates value }\end{array}$} & Knowing external business realities & 1. Recognises external business realities and adapts practices and allocates resources accordingly \\
\hline & \multirow{4}{*}{$\begin{array}{l}\text { Serving external and internal } \\
\text { stakeholders }\end{array}$} & 2. Creates market value for investors by increasing intangibles \\
\hline & & 3. Increases customer share by connecting with target customers \\
\hline & & 4. Helps line managers deliver strategy by building organisational capabilities \\
\hline & & $\begin{array}{l}\text { 5. Clarifies and establishes an employee value proposition and ensures employees have the abilities to do } \\
\text { their jobs }\end{array}$ \\
\hline & \multirow[t]{4}{*}{ Crafting HR practices } & 6. Manages people processes in ways that add value \\
\hline & & 7. Manages performance-management processes and practices in ways that add value \\
\hline & & 8. Manages information processes and practices in ways that add value \\
\hline & & 9. Manages work-flow processes and practices in ways that add value \\
\hline & \multirow[t]{2}{*}{ Building HR resources } & 10. Has a clear strategic planning process for aligning HR investments with business goals \\
\hline & & 11. Aligns its organisation with the strategy of the business \\
\hline & \multirow[t]{3}{*}{ Ensuring HR professionalism } & 12. Has staff who play clear and appropriate roles \\
\hline & & 13. Builds staff ability to demonstrate HR competencies \\
\hline & & 14. Invests in professionalism through training and development experiences \\
\hline
\end{tabular}

\section{Building human resources}

Effective HR leaders align their departments with the organisations that they serve and match their resources with business requirements. At the top, HR should help to make the whole corporation greater than the sum of its parts and to implement practices that support corporate strategies, build shareholder value and shape the corporate image (Ulrich \& Brockbank, 2005).

Boxall and Purcell (2003) stated that strategic HRM is concerned with explaining how HRM influences organisational performance. Strategic HRM is based on HRM principles incorporating the concept of strategy. Wright (1992) added to this by highlighting two important dimensions that distinguish strategic HRM from traditional HRM. This entails the linking of HRM practices with the strategic management process of an organisation and coordination or congruence among the various HRM practices.

Hagen (1998) explained that the role of a strategic business partner requires not only a shift in thinking on the part of HR professionals but, more importantly, also a shift in behaviour. He mentioned that, by understanding their new roles and associated behaviours, HR professionals are better equipped to partner with business line and executives to become a strategic business partner.

Lawler and Mohrman (2003) argued that the HR function can make and increasingly is making significant contributions to building an organisation that is staffed by the right human capital to carry out the work of the organisation and work according to its business strategy. This aspect is specifically investigated in this study.

\section{HR professionalism}

HR professionals are employee advocates charged with ensuring that the employer-employee relationship is one of reciprocal value. Besides advocating for employees today, they also build the future workforce as human-capital developers. They are furthermore functional experts, designing and delivering HR practices that ensure individual ability and create organisational capability. As strategic partners, they help line managers at all levels to reach their goals. And, to tie it all together, they should be genuine leaders, credible both within their HR function and to those outside (Ulrich \& Brockbank, 2005).

Christensen (2005) agreed that HR professionals are poised to assume major responsibilities and should become key players in the evolution of business strategy.
Hagen (1998) stated that HR professionals should demonstrate skills and knowledge in change management, strategic HR planning, talent management, merger and acquisition integration and rationalisation, global team development and strategic diversity.

\section{Research questions}

Ulrich and Brockbank (2005) developed a framework for the assessment of HR functions that draws on an 18-year study of more than $29000 \mathrm{HR}$ professionals and line managers worldwide. The framework provides value-focused criteria for HR and identifies the actions that HR should take to become a strategic business partner. They believed that the emphasis for HR should be on deliverables - not processes - and on the contribution of value.

Ulrich and Brockbank (2005) stated that, for HR to create value, HR should know the meaning of value. This includes the understanding of the external business reality of technology, of economic and regulatory issues and of workforce demographics that affect its organisation. HR should also know its internal stakeholders, customers and investors, and what they value. The framework furthermore examines how HR practices add value by handling the flow of people, the flow of performance management, the flow of information and the flow of work.

To further our understanding, we assessed the HR function of an organisation (explained under the research method) by applying the value-proposition model by Ulrich and Brockbank (2005). The research questions addressed in this study were as follows:

- Can a traditional HR function be evaluated to determine the degree of strategic alignment of the HR function within the strategic business objectives of the organisation?

- Has the HR function of the organisation completed the transformation to become a successful strategic business partner?

The framework is presented in Table 1, which illustrates the five elements and 14 criteria of the value proposition.

The objective of this study was to assess, in qualitative terms, whether the HR function of a mining company meets the requirements of the five elements and 14 criteria by Ulrich and Brockbank (2005) of becoming a strategic business partner. The organisation first needed to become a successful strategic business partner before it could proceed to the next development phase of human-capital metrics.

The rest of the article's structure is as follows: A description of the research design entailing a detailed description of the 
research approach, strategy and method follows. The findings of the case study are then discussed. Finally, recommendations, limitations and suggestions for further research are offered.

\section{RESEARCH DESIGN \\ Research approach}

According to Saunders, Lewis and Thornhill (2003), the research philosophy of researchers depends on the way in which researchers think about the development of knowledge, which also affects the way in which they go about doing research There are three views about the way in which knowledge is developed and judged as being acceptable: positivism, realism and interpretivism.

From the interpretivist position, the subjective meanings motivating people's actions should be explored to understand the phenomena. From this paradigm, the researcher is interested in understanding the views of HR personnel and line managers on the strategic contribution of the HR function to the execution of strategy. As this study was conducted within the organisation of which the researcher was an employee, the role of a practitionerresearcher was adopted.

The advantage of this position was that the first author who did the field work had extensive knowledge of the organisation and understood the complexity of what went on in the organisation. She was also, however, very conscious of the assumptions and preconceptions that were held, as this could prevent her from exploring issues that would enrich the research. The authors were therefore careful of threats to the quality of the data by being too close to the research setting (Saunders et al., 2003).

Qualitative methodology is dialectical and interpretative. During the process of interaction between the researcher and the subject, the subject's world is discovered and interpreted by means of qualitative methods. The qualitative-research paradigm refers to research that elicits participant accounts of meaning, experience or perception. It also produces descriptive data in the participant's own written or spoken words. It thus involves identifying the participant's beliefs and values that underlie the phenomena.

\section{Research strategy}

The HR forum of the organisation was chosen as the case to be investigated in this study. A case study is defined as an empirical enquiry that investigates a contemporary phenomenon within its real-life context, when the boundaries between the phenomenon and the context are not clearly evident, and in which multiple sources of evidence are used (Saunders et al., 2003, p. 93; Yin, 1994). A case study was adopted as research strategy for the purpose of this study, as it generates answers to the questions 'Why?', 'What?' and 'How?'

\section{Research method}

'Research method' refers to the process applied to execute a research strategy. Research methods are also described as 'the way to the goal'.

\section{Research context and entrée}

As an HR practitioner and a member of the organisation, the first author had a special relationship with the HR forum. The advantage of being an employee of the organisation where the study was undertaken was that the researcher possessed knowledge of the organisation and understood the complexity of what went on in it.

The organisation is the world's leading primary producer of precious group metals. It is listed on the Securities Exchange and the Johannesburg Stock Exchange and is the sole listed entity for the group. The group is also listed on other international stock exchanges.
Each of the subsidiaries has an HR function as part of the group HR department and is managed by an HR manager. These HR managers are all part of a forum known as the HR forum, which is led by the group HR director. The different stream leaders (transformation, organisational effectiveness, talent management and HR development) are also members of the HR forum. It was the members of the HR forum who were targeted for the focus group and one-on-one interviews.

\section{Participants}

All the participants were experts in the field of $\mathrm{HR}$ and, by using the focus-group interviewing method, the participants' knowledge and experience were explored. The first author was able to examine what they thought, how they thought and why they thought that way. This is called purposive sampling, meaning that individuals with particular HR knowledge, for example, are selected for the focus groups. Focus groups were utilised to assess the HR function to determine the strategic alignment of the HR function within the organisation. Terre Blanche \& Durrheim (1999) called this convenience or opportunistic sampling. The members of the focus groups were homogenous (the participants share key features), preexisting (the groups comprise work colleagues) and concerned (the participants 'have a stake' in the outcome of the research) (Willig, 2003, p. 30). Five senior HR managers were interviewed in the individual interviews.

\section{Data collection}

The model by Ulrich and Brockbank (2005) was utilised to assess the value add of the HR function by applying the integrated HR blueprint for the transformation of the HR function as developed by Ulrich and Brockbank. In this blueprint, Ulrich and Brockbank identified five elements and established 14 criteria for HR with a value focus.

The HR function of the organisation was assessed to determine the elements of the HR value framework that were and were not in place. Assessments rely on the assembling of data, a task that involves two issues: content and process. Content deals with the information that is collected and process with how it is collected (Ulrich \& Brockbank, 2005, p. 16).

The five elements of the HR value proposition indicated the framework used to assess the overall HR function in the organisation. Based on the identified five elements, an interview protocol was created to assess the HR business-partner role within the organisation.

Qualitative interviews and document reviews were used. The two different types of qualitative interviews that were used were one-on-one and focus-group interviews. One focus-group interview was conducted with selected HR managers and the one-on-one interviews were conducted with selected line managers and other senior managers within the organisation. The overall purpose of the focus group and one-on-one interviews was to explore the topic in depth through group and individual discussions.

Solicited document reviews were done to obtain comprehensive and historical information on the HR value add according to the five elements and 14 criteria for $\mathrm{HR}$ with a value focus identified by Ulrich and Brockbank (2005).

\section{- One-on-one interviews}

A general interview-guide approach was used to ensure that the same general areas of information were collected from the various interviewees. This interview approach provided more focus than the conversational approach but still allowed a degree of freedom and adaptability in obtaining information from the interviewees (McNamara, 1999).

Interview guides ensure the good use of limited interview time, make the interviewing of multiple subjects more systematic 
and comprehensive and help to keep interactions focused. In keeping with the flexible nature of qualitative-research design, interview guides can be modified over time to focus attention on the areas of particular importance or to exclude questions that the researcher finds unproductive for the goals of the research (Hoepfl, 1997).

\section{- Focus-group interviews}

Focus groups are powerful means of evaluating services or testing new ideas. Basically, focus groups are interviews but of six to ten people at the same time in the same group. A great deal of information can be obtained during a focus-group session (McNamara, 1999).

According to McNamara (1999), the advantage of focus-group interviews is that common impressions can be obtained from participants quickly and reliably, with much range and depth of information.

McNamara (1999) also mentioned that the challenges are that it can be hard to analyse responses and that a good facilitator is needed for safety and closure. He furthermore mentioned that it can be difficult to schedule six to eight people together for a session.

The interviews were structured according to sound ethical principles:

- The whole objective of the research was explained

- Techniques were used to help the individuals to express themselves.

The reliability of the interviews was assured through a precise description of the situation and through the method of data collection, analysis and interpretation. Complete notes were made of the interviews that took place, giving an exposition of the interviewer's influence within the research framework.

\section{Data recording}

Data were captured by means of field notes. According to Schurink (2004), field notes are the written account of what researchers hear, see, experience and think in the course of the collecting of and reflecting on data in qualitative-research studies. They are not merely summaries of events but detailed reproductions of what takes place. The researcher in the present study typed the field notes on a computer, where they were safely stored. This saved time during the marking, coding, copying and moving of parts of the field notes to various texts. Schurink also mentioned that field notes are a step towards data analysis. He stated that note writing forces researchers to think clearly about particular observations, what exactly happened, where events occurred, when events took place, who the actors were and how they experienced events.

Notes on aspects such as non-verbal communication between the interviewer and the subject, and the physical circumstances in which the interview took place were written down. The researcher ensured that all the notes made in this data-collection phase were then clearly and systematically typed. A coding system was utilised to store the data in the analytic files. According to Schurink (2004), the task of coding by a researcher is to recognise persistent words, phrases and themes within the data for later retrieval and resorting. The coding system was managed manually.

\section{Solicited documentation review}

Hoepfl (1997) claimed that another source of information that can be invaluable to qualitative researchers is the analysis of documents. Such documents may include official records, letters, newspaper accounts, diaries and reports as well as the published data used in a review of literature. For the purpose of this study, the documentation that was reviewed comprised strategic planning documents for 2006/7;
- performance-management templates

- policy documents

- procedures

- minutes of meetings during 2006/7.

Data analysis

Saunders et al. (2003) distinguished between the deductive and the inductive approach, as follows:

- Deductive: To develop a theory and hypothesis and design a research strategy to test the hypothesis

- Inductive: To collect data and develop theory as a result of data analysis.

According to Saunders et al. (2003), the deductive approach owes more to positivism and the inductive approach to interpretivism. Recently, qualitative researchers have paid less attention to differences and have accepted a mix between the two.

This study aimed to obtain the experiences (the opinion and understanding) of individuals on the strategic contribution of the HR function to the execution of strategy (the context). The most appropriate approach for the sake of this study was therefore to follow an inductive-qualitative approach, as this approach allowed the study of the phenomena as they unfolded in the real situations, without manipulation, as interrelated wholes rather than as split-up, discreet, predetermined variables.

'The aim of data analysis is to transform information (data) into an answer to the original research question' (Saunders et al., 2003, p. 47). Qualitative data consist of words and observations, not numbers. As with all data, analysis and interpretation are required to bring order and understanding.

For the purpose of this study, we used a content-analysis approach, as narrative data needed to be analysed and interpreted. The focus-group interviews produced narrative data in the form of full transcripts and notes and the individual interviews produced data in the form of notes, a summary or word-to-word transcripts. Documents, reports and articles served as evaluation data.

The core of qualitative-data analysis relies on three related processes: the description of phenomena, the classification of the phenomena and the interconnectedness of the concepts. The first phase was therefore to develop a thorough and comprehensive description of the phenomenon under study. The second was to classify the data that formed the conceptual foundation upon which the interpretation and explanation were based. The third was to make connections among the building blocks of the concepts of the analysis. The analysis of the qualitative results and findings is presented here.

\section{RESULTS}

\section{Element 1: Knowing external business realities}

The findings on knowing external business realities are presented in Table 2.

The findings in Table 2 may be summarised as follows:

- The content of the themes and the exemplary quotes indicated the challenges that the organisation faced in dealing with external business realities

- The HR function was aware of the basic trends relative to the technological, economic and regulatory issues and contributed meaningfully to management discussions in this regard

- According to solicited document reviews that were done, the organisation reacted to challenges posed by emerging external business realities by initiating an enhanced safetyimprovement plan

- It is thus evident that the organisation was fully aware of external business realities and that HR played an integral part as the driver of this change and of business transformation

- All HR strategies were aligned with the enhanced safetyimprovement plan and the overall business strategy. 
TABLE 2

Emerging themes pertaining to Element 1: Knowing external business realities

\begin{tabular}{|c|c|c|c|}
\hline ELEMENT & CRITERION & EMERGING THEMES & EXEMPLARY SUPPORTIVE EVIDENCE \\
\hline Element 1 & Criterion 1 & Themes & Quotes \\
\hline \multirow[t]{4}{*}{$\begin{array}{l}\text { Knowing external business } \\
\text { realities }\end{array}$} & $\begin{array}{l}\text { Recognises external business } \\
\text { realities and adapts practices and } \\
\text { allocates resources accordingly }\end{array}$ & - Current market share & $\begin{array}{l}\text { 'The most critical element is the current market share and the } \\
\text { organisation's control of the majority of known resources.' }\end{array}$ \\
\hline & & $\begin{array}{l}\text { - Social, legal and economic } \\
\text { challenges }\end{array}$ & $\begin{array}{l}\text { 'The resources are vulnerable, unless the organisation addresses } \\
\text { the social, legal and economic challenges successfully.' }\end{array}$ \\
\hline & & - Undergoing of transformation & $\begin{array}{l}\text { 'The organisation is currently an organisation undergoing } \\
\text { transformation and HRs need to understand the changing business } \\
\text { context.' }\end{array}$ \\
\hline & & $\begin{array}{l}\text { - Alignment of HR strategies and } \\
\text { practices }\end{array}$ & $\begin{array}{l}\text { 'The organisation has gone through a restructuring process of the } \\
\text { Mining and Processing divisions to enable the Mine Manager to } \\
\text { focus on greater efficiency in the extraction of the metal.' } \\
\text { 'HR will need to align this HR Strategy to the Safety Improvement } \\
\text { Initiative and will need to keep track of the environment.' }\end{array}$ \\
\hline
\end{tabular}

TABLE 3

Emerging themes pertaining to Element 2: Serving external and internal stakeholders

\begin{tabular}{|c|c|c|}
\hline ELEMENT & CRITERION & EMERGING THEMES \\
\hline Element 2 & Criterion 2 & Themes \\
\hline \multirow[t]{10}{*}{$\begin{array}{l}\text { Serving external } \\
\text { and internal } \\
\text { stakeholders }\end{array}$} & $\begin{array}{l}\text { Creates market } \\
\text { value for investors by } \\
\text { increasing intangibles }\end{array}$ & - Competent people as enablers \\
\hline & & - Effective talent-management practices \\
\hline & Criterion 3 & Themes \\
\hline & $\begin{array}{l}\text { Increases customer } \\
\text { share by connecting } \\
\text { with target customers }\end{array}$ & - Competence taken to the workforce \\
\hline & & - Management of expectations \\
\hline & & - Alignment, integration and application of processes \\
\hline & Criterion 4 & Themes \\
\hline & $\begin{array}{l}\text { Helps line managers } \\
\text { deliver strategy by } \\
\text { building organisational } \\
\text { capabilities }\end{array}$ & $\begin{array}{l}\text { - Lacking of people skills in line managers } \\
\text { - Handover of responsibilities from HRs to line managers }\end{array}$ \\
\hline & Criterion 5 & Themes \\
\hline & $\begin{array}{l}\text { Clarifies and establishes } \\
\text { an employee value } \\
\text { proposition and ensures } \\
\text { employees have the } \\
\text { abilities to do their work }\end{array}$ & $\begin{array}{l}\text { - } \quad \text { Training as entity on its own } \\
\text { - } \quad \text { Overload of interventions }\end{array}$ \\
\hline & & - Development of people as a whole \\
\hline
\end{tabular}

EXEMPLARY SUPPORTIVE EVIDENCE

\section{Quotes}

'Competent people are the enabler to the achievement of goals which is to work safely, on target, doing the right thing right the first time, efficiently and effectively.'

'Effective talent management has an impact on most priorities and the current attrition rate is concerning.' 'The war for talent exists! Also in HR.'

Quotes

'Competence needs to be taken to the workplace, whereby the best performing specialist is becoming the HR person to train the people in their normal production area.

'HR Practitioners must start managing the expectations of their customers and stakeholders in order to proof their valued contribution and success.'

'HR is delivering - interventions, models, practices and matrixes are in place, which is good. The only problem is the alignment, integration and application of processes.' Quotes

'Line managers are lacking people skills and are not adequately equipped to take up the role of human capita managers as opposed to their daily production activities.'

'The organisation will need to plan strategically how HRs will hand over responsibilities to Line.'

Quotes

'Training is seen as a separate entity from the work environment and there is a lack of integration between trainer, trainee and manager. Thus the benefit of training is lost!'

'There is currently an overload of interventions and it dilutes the purpose.'

'A new approach to people development is needed where a person will be developed as a whole. Not training for competence, but for completeness.
The evidence provided confirmed that the organisation, together with the HR function, was aligned with criterion 1, as it recognised external business realities, adapted practices and allocated resources accordingly.

\section{Element 2: Serving external and internal stakeholders}

The findings on serving external and internal stakeholders are presented in Table 3.

In summary, the analysis of the data indicated that line managers were starting to accept HR interventions in their management roles. Line managers should experience a more integrated, aligned and standardised approach from HR.
The document reviews indicated that the HR function was producing value to stakeholders by focusing on four strategic issues over a three-year period:

- 'War for Talent' and the addressing of skills shortages

- An HR information-system project

- An HR review process

- The implementation of the enhanced safety-improvement plan.

Focus on the 'War for Talent' and the addressing of skills shortages will create market value for shareholders, as the right people with the right skills doing the right things will be attracted and retained. Focus on the addressing of skills shortages will ensure that employees have the abilities to do their jobs (criteria 2 and 5).

- The HR review process was undertaken by the HR department as a means to ensure that the HR function was 
TABLE 4

Emerging themes pertaining to Element 3 : Crafting HR practices

\begin{tabular}{|c|c|c|c|}
\hline ELEMENT & CRITERION & EMERGING THEMES & EXEMPLARY SUPPORTIVE EVIDENCE \\
\hline Element 3 & Criterion 6 & Themes & Quotes \\
\hline \multirow[t]{9}{*}{$\begin{array}{l}\text { Crafting HR } \\
\text { practices }\end{array}$} & $\begin{array}{l}\text { Manages people } \\
\text { processes in ways } \\
\text { that add value }\end{array}$ & $\begin{array}{l}\text { - Necessity of culture evolution } \\
\text { in HR }\end{array}$ & $\begin{array}{l}\text { 'A culture evolution is needed and it will start with the building of capacity of HR personnel, } \\
\text { competence of employees, building of trusting relationships and creating an environment that is } \\
\text { conducive for change.' }\end{array}$ \\
\hline & & $\begin{array}{l}\text { - Identification and retention of } \\
\text { talented employees }\end{array}$ & $\begin{array}{l}\text { 'Strategic alignment and focus are crucial and HRs need to focus on attracting the right people, } \\
\text { effective talent identification, focussed development and retention of skills. In order to move from } \\
\text { good to great we need to retain the right thinkers with the right capabilities.' }\end{array}$ \\
\hline & Criterion 7 & Themes & Quotes \\
\hline & $\begin{array}{l}\text { Manages } \\
\text { performance- } \\
\text { management } \\
\text { processes and } \\
\text { practices in ways } \\
\text { that add value }\end{array}$ & $\begin{array}{l}\text { - When are HRs successful? } \\
\text { - Focus on individual } \\
\text { performance }\end{array}$ & $\begin{array}{l}\text { 'How can one determine whether HR is a high performing team?' } \\
\text { 'Is HR successful when it has reached its targets or when the customer satisfaction has } \\
\text { improved?' } \\
\text { 'Currently the performance of HR is measured by means of an Individual Performance Agreement } \\
\text { and only for HR professionals in supervisory and management positions. The system must be } \\
\text { rolled out to all levels to improve efficiency and effectiveness.' }\end{array}$ \\
\hline & Criterion 8 & Themes & Quotes \\
\hline & $\begin{array}{l}\text { Manages } \\
\text { information } \\
\text { processes and } \\
\text { practices in ways } \\
\text { that add value }\end{array}$ & 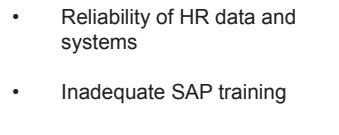 & $\begin{array}{l}\text { 'We cannot rely on the information provided by the HR system.' } \\
\text { 'The bridge between IT and HR must be strengthened.' } \\
\text { 'The SAP training is not adequate. It only provides trainees with access to a screen and the } \\
\text { training does not address the holistic process.' }\end{array}$ \\
\hline & & $\begin{array}{l}\text { Necessity of relevant metrics } \\
\text { and data integrity }\end{array}$ & $\begin{array}{l}\text { 'HR needs to ensure its impact on the organisation by implementing relevant metrics, but the } \\
\text { systems to provide accurate and relevant data are lagging.' } \\
\text { 'HRs' inability to provide data of integrity is hampering their operational excellence.' }\end{array}$ \\
\hline & Criterion 9 & Themes & Quotes \\
\hline & $\begin{array}{l}\text { Manages work-flow } \\
\text { processes and } \\
\text { practices in ways } \\
\text { that add value }\end{array}$ & $\begin{array}{l}\text { - HR value chain } \\
\text { - Simplicity of systems and } \\
\text { processes }\end{array}$ & $\begin{array}{l}\text { 'HR must manage labour and talent.' } \\
\text { 'The HR value chain needs to be implemented to its fullest by putting the necessary systems and } \\
\text { processes in place.' } \\
\text { 'The simplicity of systems and processes is causing problems for HR and a total mindset change } \\
\text { is needed.' }\end{array}$ \\
\hline
\end{tabular}

TABLE 5

Emerging themes pertaining to Element 4: Building HR resources

\begin{tabular}{|c|c|c|c|}
\hline ELEMENT & CRITERION & EMERGING THEMES & EXEMPLARY SUPPORTIVE EVIDENCE \\
\hline Element 4 & Criterion 10 & Themes & Quotes \\
\hline \multirow[t]{6}{*}{$\begin{array}{l}\text { Building HR } \\
\text { resources }\end{array}$} & $\begin{array}{l}\text { Has a clear strategic planning } \\
\text { process for aligning HR } \\
\text { investments with business } \\
\text { goals }\end{array}$ & - Linking of strategy to HR infrastructure & $\begin{array}{l}\text { 'Workforce strategy needs to be linked to the HR infrastructure to ensure the } \\
\text { right resources to address the need for a competent workforce.' } \\
\text { 'HR must be careful not to define its mission too broadly, specifically at } \\
\text { strategic level.' }\end{array}$ \\
\hline & & - Challenge of size of organisation & $\begin{array}{l}\text { 'The size of the organisation is a challenge and it forces the HR function to } \\
\text { create specialist positions, which is causing silo effects and crisis managemen } \\
\text { without specific focus.' }\end{array}$ \\
\hline & Criterion 11 & Themes & Quotes \\
\hline & $\begin{array}{l}\text { Aligns its organisation to the } \\
\text { strategy of the business }\end{array}$ & - HR development emphasis & $\begin{array}{l}\text { 'The efficiency and effectiveness of the organisation are directly linked to } \\
\text { HR development and the development of the person as a whole has a huge } \\
\text { impact on cost efficiency and the way the organisation mines.' }\end{array}$ \\
\hline & & - Resource allocation & $\begin{array}{l}\text { 'HR resources need to be allocated to specific focus areas, taking diversity } \\
\text { and change into consideration.' }\end{array}$ \\
\hline & & - Transactional vs. strategic-issues focus & $\begin{array}{l}\text { 'The organisation must relook at its business model and must do a comparison } \\
\text { of the HR function as an internal service provider, whose focus needs to be on } \\
\text { strategic issues and not on competing with the external service providers.' } \\
\text { 'There is currently a lack of strategic direction and no collective thought in } \\
\text { solutions to problems.' } \\
\text { 'HR is currently fighting fires and is falling behind on transactional issues and } \\
\text { there is no time to concentrate on strategic issues.' }\end{array}$ \\
\hline
\end{tabular}

positioned to supportbusiness imperatives and line managers to deliver on its mandate, especially in view of expansion requirements. It was envisaged that the implementation of the HR review would address criteria 3 and 4 successfully.

\section{Element 3: Crafting HR practices}

The findings on crafting HR practices are presented in Table 4 . The analysis of the data indicated that

- culture change was needed within HR and effective talentmanagement practices were imperative

- a new culture was evolving and the need for more effective talent-management processes was realised (criterion 6)

- the content of the themes and the exemplary quotes indicated that the HR function faced huge challenges with regard to its information system and the integrity of its data

- the HR information-system project was to address the challenges with regard to information, data integrity and the flow of information (criterion 8)

- the performance-management process was still individually based and focused on inputs rather than results (criterion 7)

- the work-flow processes and practices were still simplistic and not managed in ways that added value (criterion 9).

\section{Element 4: Building HR resources}

The findings on building HR resources are presented in Table 5 . In summary, the analysis of the data indicated that

- the size of the organisation posed many challenges to the 
TABLE 6

Emerging themes pertaining to Element 5: Ensuring HR professionalism

\begin{tabular}{|c|c|c|c|}
\hline ELEMENT & CRITERION & EMERGING THEMES & EXEMPLARY SUPPORTIVE EVIDENCE \\
\hline Element 5 & Criterion 12 & Themes & Quotes \\
\hline \multirow[t]{7}{*}{$\begin{array}{l}\text { Ensuring HR } \\
\text { professionalism }\end{array}$} & $\begin{array}{l}\text { Has staff who play clear } \\
\text { and appropriate roles }\end{array}$ & $\begin{array}{ll}\text { - } & \text { Talent war } \\
\text { Competence and capabilities of } \\
\text { HR professionals }\end{array}$ & $\begin{array}{l}\text { 'Getting and keeping talent are a challenge even in the HR function.' } \\
\text { 'The overall competence and capabilities of HR professionals need to be improved, } \\
\text { especially in the organisational development and talent management areas.' } \\
\text { 'Standardisation is taking too long, operational HR is not taking ownership and capacity } \\
\text { problems to deliver on most sites are posing challenges.' } \\
\text { 'Responsibility for standardisation needs to be owned by operations and cannot be done } \\
\text { from a central point.' } \\
\text { 'Role clarity and an alignment of efforts will ensure success within the HR's function and } \\
\text { it will ensure that the client experiences an integrated and focused HR approach to fulfil } \\
\text { the business requirements.' }\end{array}$ \\
\hline & Criterion 13 & Themes & Quotes \\
\hline & $\begin{array}{l}\text { Builds staff ability } \\
\text { to demonstrate HR } \\
\text { competencies }\end{array}$ & $\begin{array}{l}\text { - } \quad \text { Coaching } \\
\text { - } \quad \text { Lack of competence }\end{array}$ & $\begin{array}{l}\text { 'I feel that the most experienced practitioner needs to coach the young inexperienced } \\
\text { workforce.' } \\
\text { 'Passion and drive are not a problem in HRs, they lack competence.' }\end{array}$ \\
\hline & Criterion 14 & Themes & Quotes \\
\hline & $\begin{array}{l}\text { Invests in HR } \\
\text { professionalism } \\
\text { through training } \\
\text { and development } \\
\text { experiences }\end{array}$ & $\begin{array}{l}\text { - Lack of depth of experience in } \\
\text { HRs } \\
\text { - Necessity of improvement in } \\
\text { maturity levels }\end{array}$ & $\begin{array}{l}\text { 'Due to the high turnover rate of HR professionals, there is a lack of depth of experience } \\
\text { and the labour forces need to be stabilised at all supervisory levels.' } \\
\text { 'I feel that the maturity levels of HR professionals need to improve and they need to } \\
\text { show responsibility and accountability for their work.' }\end{array}$ \\
\hline & & $\begin{array}{l}\text { - Giving and receiving of } \\
\text { constructive criticism }\end{array}$ & $\begin{array}{l}\text { 'HRs must give and be able to receive constructive criticism and must improve their } \\
\text { emotional stability and EO.' }\end{array}$ \\
\hline & & Necessity of change in mindset & 'A mind set change is needed in order to live the values of the organisation.' \\
\hline
\end{tabular}

HR function, as all strategies were directly linked to HR management

- effective resource allocation had a direct impact on HR's ability to implement practices that meet business requirements and support strategies

- due to the amount of transactional issues, HR had no resources (time or people) to concentrate on strategic issues

- the HR review process was addressing the structural changes that should take place within the HR function to address criteria 10 and 11 effectively.

\section{Element 5: Ensuring HR professionalism}

The findings on ensuring HR professionalism are presented in Table 6. In summary, the findings suggested the following:

- the content of the emerging themes and exemplary quotes indicated that the organisation experienced difficulty in retaining HR professionals and that the 'War for Talent' was not a reality within $\mathrm{HR}$

- HR's competence, maturity and depth of experience were questionable.

According to the HR director, there were three primary tasks that should be performed:

- HR should lead business transformation

- HR should align the HR strategy with the enhanced safetyimprovement plan initiative

- HR should drive cultural change.

To achieve these tasks, HR should

- understand the changing business contextkeep

- track of the environment

- develop the capabilities needed to drive transformation

- develop a sense of curiosity.

It was clear that, for HR to be perceived as professional, the HR vision, values and defined tasks should be implemented and behaviour that demonstrated support of the values should be observable to ensure excellent service delivery and credibility among stakeholders (criteria 12, 13 and 14).

\section{DISCUSSION \\ Knowing external business realities}

The organisation is undergoing transformation and HR should transform accordingly. The newly appointed CEO demands

improved safety performance, higher productivity, a caring culture and performance excellence.

According to Sullivan (2005), HR transforms only if the CEO demands change, instils accountability within $\mathrm{HR}$, and demands speed, quality, cost efficiency and improved bottom-line impacts. This, together with the context of increasing globalisation, is imperative for HR to keep abreast with the latest developments and to be aware of the influence of external business realities on HR's performance. HR professionals being 'at the table' requires more than just simple familiarity with HR issues or internal operations; it requires knowledge about the driving forces that shape the fundamental nature of business (Boudreau, 2007; Ulrich \& Brockbank, 2005).

It is evident from the findings that the organisation realises the external business realities and that HR plays an integral part as the driver of this change and of the business transformation. All HR strategies should be aligned with the enhanced safetyimprovement plan and the overall business strategy. This aligns with the views of Brown (2003), Christensen (2005) and Hagen (1998) that HR transformation entails the integration of people issues with business issues. The evidence confirms that the organisation, together with the HR function, is aligned to criterion 1 , as it recognises the external business realities and adapts practices and allocates resources accordingly.

\section{Serving external and internal stakeholders}

From the analysis of the results, it is evident that HR should focus more on effective and efficient talent acquisition and retention to create market value for its investors. As previously mentioned, competent people are the enablers to the achievement of goals, and higher competitive advantage can be gained by increasing the competence of the workforce. HR is, however, delivering, which 
is evident in the number of interventions implemented and in the models, practices and matrixes that exist. The only problem is the lack of the integration of interventions and alignment with the overall objectives of the organisation, which is causing line managers to be overloaded with different initiatives and the purpose of the interventions to be diluted. The results indicate that the line managers are starting to accept HRM interventions in their management roles but need a more integrated, aligned, standardised approach from HR.

As previously mentioned, Christensen (2005) emphasised that HR should serve line managers in such a way that they do not attempt to resolve people issues without advice from and consultation with HR. It is clear that HRM is becoming integral to business operations, as it was recommended that competence be taken to the workforce. HR can be successful only if it starts to manage the expectations of external and internal stakeholders successfully. By focusing on strategic issues, HR can address the expectations of stakeholders through the effective management of the environment. Effective management of the environment results in employee satisfaction and a defined employee value proposition, as employee productivity and retention will improve. Through this defined value proposition, HR can demonstrate to its stakeholders its strategic contribution to the overall achievement of the organisational goals.

\section{Crafting HR practices}

The organisation is challenged by high attrition rates. Effective and efficient talent-management practices are imperative in the retention of people skills and of the competencies needed to meet business results. The results from the analysis indicate that the current performance-management processes and practices are not measuring the results of HR but rather the inputs. It is still all about the activity - measuring the effectiveness of HR in terms of traditional measures - and not about the impact of the activity employed. It is evident that the organisation is experiencing problems with the reliability and integrity of the data from the HR information system, to the extent that the line managers are of the opinion that they cannot rely on the data provided by HR.

Cantrell (2005), Higgins (2005), Mayo (2004), Singh and Latib (2005) and Sullivan (2005) presented much evidence of the importance of the availability of data and of proper metrics to prove HR strategic contribution to business results.

Ulrich and Brockbank (2005) mentioned that, for credibility, HR professionals should not only understand the logic of external trends but should also have data to back up their position and know where to find such data.

The current inability of the HR information system to provide accurate data is destroying HR's knowledge foundation and HR professionals are not equipped to start meaningful conversations about customers, shareholders, management or employees.

\section{Building HR resources}

The content of the emerging themes and exemplary quotes indicate that it is imperative that the workforce strategy be linked to the HR infrastructure to ensure the right resources to address the needs of the organisation. The size of the organisation is posing a challenge to $\mathrm{HR}$ and is causing HR to concentrate more on transactional activities and to neglect strategic issues due to resource problems.

It is evident from the analysis of the results that the HR function within the organisation is lacking strategic direction and that it tends to over-promise and under-deliver. This may be a result of HR resources not being allocated to specific focus areas and not being aligned to business requirements. The ultimate test for HR is to determine how successfully it serves its customers, line managers and employees. This is measured in terms of effectiveness and efficiency. The effectiveness of HR efforts is measured by the delivery of value through intangibles and through the capabilities and abilities of people. The efficiency of HR efforts is measured by the transactions performed through standardised processes. Wright (1992) emphasised that the linking of HRM practices with the strategic-management process of an organisation and the coordination or congruence among various HRM practices are crucial.

It is also recommended that the organisation revisit its business model for $H R$ and the different generic patterns that $H R$ normally assumes, these being HR functional organisation, HR shared services and embedded HR. The HR review process is addressing the structural changes that should take place within the HR function to ensure strategic alignment between the HR function and business requirements.

\section{Ensuring HR professionalism}

The analysis of the results indicates that the organisation is experiencing difficulty in retaining HR professionals and that the 'War for Talent' within HR is a reality (Boudreau \& Ramstad, 2007). As previously mentioned, passion and drive are not a problem in HR but rather a lack of competence, especially in the organisational-development and talent-management functions. Due to the high turnover rate of HR professionals, there is a lack of depth in experience, the maturity levels of the new entrants are low and there is a lack of accountability and responsibility. Role clarity is also still problematic. It is thus evident that the HR professionals within the organisation are not yet in a position to fulfil their future roles as strategic partners, which will leverage their centres of expertise. Hall (2005) mentioned that HR should focus more on talent acquisition and retention; the organisation is currently not very successful in this area, since processes are not yet integrated or supported by technology for greater efficiency.

Ulrich and Brockbank (2005) described the various roles of HR professionals as being strategic partner, functional expert, human-capital developer, employee advocate and HR leader. For the organisation to ensure HR professionalism, it should have HR practitioners who play clear and appropriate roles and whose ability is developed through training with a view to the achievement of the required HR competencies. It is clear that, for $\mathrm{HR}$ to be perceived as professional, the HR vision, values and defined tasks should be implemented and the behaviour that demonstrates support of the values should be observable to ensure excellent service delivery and credibility among the stakeholders. This view is supported by Hagen (1998) and Christensen (2005) in literature.

\section{Conclusion}

The purpose of this study was to assess, in a qualitative manner, whether the specific organisation's HR function meets the requirements of the five competency elements and 14 criteria by Ulrich and Brockbank (2005) to become a strategic business partner (hence the dichotomous categories). The results are indicated in Table 7.

Within this context, there is evidence that the HR function of the organisation is starting its transition from an operational HR to a more strategically focused HR. The organisation is aware of its external business realities and strategies are being developed but the implementation of the strategies, however, seems to be problematic. The organisation is also starting to become more focused on maximum value from people but it needs to integrate, standardise and align processes more effectively. Proof of HRM becoming an integral part of business operations includes business partners who understand the business and HRM serving its external and internal stakeholders more effectively. Line managers are also accepting HRM interventions in their management roles and are valuing HRM expertise, evidence of more effective HRM. HR practitioners are furthermore becoming more professional, as there is focus on specific tasks 
TABLE 7

Summary of research findings pertaining to meeting the 14 criteria

\begin{tabular}{|c|c|c|c|}
\hline \multirow{2}{*}{$\begin{array}{l}\text { ELEMENTS OF THE HR } \\
\text { VALUE PROPOSITIONS }\end{array}$} & \multirow{2}{*}{ CRITERIA FOR THE TRANSFORMATION OF THE HR FUNCTION } & \multicolumn{2}{|c|}{ ALIGNMENT TO CRITERION } \\
\hline & & FULLY & PARTIALLY \\
\hline $\begin{array}{l}\text { Knowing external business } \\
\text { realities }\end{array}$ & 1. Recognises external business realities and adapts its practices and allocates resources accordingly & $\sqrt{ }$ & \\
\hline \multirow{4}{*}{$\begin{array}{l}\text { Serving external and internal } \\
\text { stakeholders }\end{array}$} & 2. Creates market value for investors by increasing intangibles & & $\sqrt{ }$ \\
\hline & 3. Increases customer share by connecting with target customers & & $\sqrt{ }$ \\
\hline & 4. Helps line managers deliver strategy by building organisational capabilities & & $\sqrt{ }$ \\
\hline & $\begin{array}{l}\text { 5. Clarifies and establishes an employee value proposition and ensures employees have abilities to do } \\
\text { their jobs }\end{array}$ & & $\sqrt{ }$ \\
\hline \multirow[t]{4}{*}{ Crafting HR practices } & 6. Manages people processes in ways that add value & & $\sqrt{ }$ \\
\hline & 7. Manages performance-management processes and practices in ways that adds value & & $\sqrt{ }$ \\
\hline & 8. Manages information processes and practices in ways that add value & & $\sqrt{ }$ \\
\hline & 9. Manages work-flow processes and practices in ways that add value & & $\sqrt{ }$ \\
\hline \multirow[t]{2}{*}{ Building HR resources } & 10. Has a clear strategic planning process for aligning HR investments with business goals & & $\sqrt{ }$ \\
\hline & 11. Aligns its organisation with the strategy of the business & & $\sqrt{ }$ \\
\hline \multirow[t]{3}{*}{ Ensuring HR professionalism } & 12. Has staff who play clear and appropriate roles & & $\sqrt{ }$ \\
\hline & 13. Builds staff ability to demonstrate HR competencies & & $\sqrt{ }$ \\
\hline & 14. Invests in HR professionalism through training and development experiences & & $\sqrt{ }$ \\
\hline
\end{tabular}

and capabilities and as the culture within HR is starting to evolve towards service excellence.

\section{Recommendations}

Given the technological, economic and regulatory, and demographic realities of our global world, HR insight has been pushed to the forefront of business success. Now, more than ever, business success comes from HR, and the 'DNA' for HR's success is the HR value proposition. With this value proposition, the HR profession has a point of view about what can and should exist for all stakeholders, a set of standards directing HR investments in strategy, structure and practice, and a template for ensuring that each HR professional contributes to the organisation. The HR value proposition is the blueprint for the future of HR (Ulrich \& Brockbank, 2005).

The effectiveness of HR, however, is currently not measured by inputs but rather by results. In many organisations, there is a significant gap between the stated objectives of the HR functions and the methods that the HR functions use to measure their effectiveness.

It is recommended that the HR function of the organisation concerned be assessed thoroughly through a quantitative audit to determine which elements of the HR framework are in place in the organisation and which are not. This assessment will provide the HR function with an indication of the strengths and weaknesses of the HR function and will assist the practitioners to focus efforts on the elements in need of attention. With this understanding, the HR professionals will be proactive rather than reactive, control their destiny and add sustainable value. Ultimately, with this understanding, the HR professionals will be able to engage in conversations with all the organisational stakeholders and bring sustainable value to the table (Ulrich \& Brockbank, 2005).

\section{Limitations}

It must be kept in mind that this study was conducted in only one organisation in the mining industry and that no further assumptions can therefore be made with regard to the mining industry as a whole. The number of participants was also limited due to difficulty experienced in the scheduling of a sufficient number of participants at a given time. A limited number of line managers was also interviewed and their inputs would have been valuable to the process. The quality of the data may be questioned due to the fact that the researcher was very close to the research setting and that the assumptions and preconceptions of the researcher may have prevented issues being explored that could have enriched the research.

\section{Suggestions for further research}

Cantrell (2005, p. 86) stated that 'even professional HR consultants will admit that there currently exist few clearly defined performance measures for HR. As a result, the overall knowledge within HR is uneven' Singh and Latib (2005) also mentioned that scientific research in this area is limited and, if present at all, is often shoddy.

Cantrell (2005) further stated that HR is facing such increased pressure to demonstrate accountability for human capital to the business and to the CEO that effective HR metrics have become imperative. Research has shown that organisations that take a more rigorous, metrics-based approach to assess the impact of HR interventions on business results have far better business results than organisations that do not use such metrics.

The lack of scientific thinking in human-capital management remains virtually universal. Cascio and Boudreau (2008) concluded that 'intangible' does not translate into 'unmeasurable'. Human-capital metrics and benchmarking are two areas that need revamping through scientific thinking. The use of metrics in HR is slowly growing but many of the typical metrics have no causal relationships to the desired outcomes. It is therefore proposed that HR executives be given the opportunity to sit at the executive-committee table as strategic partners by adopting new innovative solutions from the marriage of science, technology and intellectual resources (Singh \& Latib, 2005).

We believe that considerable future work is still required to develop a method to identify human-capital metrics for the HR function within a mine and, more particularly, to search and to find relevant data to develop the right metrics that will link HR performance and strategic business objectives. 


\section{REFERENCES}

Boudreau, J.W., \& Ramstad, P.M. (2007). Beyond HR: The new science of human capital. Boston: Harvard Business School Press.

Boxall, P., \& Purcell, J. (2003). Strategy and HR management. Basingstoke: Palgrave Macmillan.

Brown, D. (2003, 17 November). HR steps to prove strategic value. Canadian HR Reporter, pp. 20-21.

Cantrell, S. (2005). How smart HR departments win with business intelligence. In A. Warton (Ed.), People, performance, profit: Maximizing return on human capital investments, (pp. 84-87). San Francisco: Montgomery Research, Inc.

Cascio, W.F., \& Boudreau, J.W. (2008). Investing in people: Financial impact of human resource initiatives. Upper Saddle River: Pearson Education.

Christensen, R. (2005). Roadmap to strategic human resources. Turning a great idea into a business reality. Retrieved July 28, 2008, from http://www.getAbstract.com

Conner, J., \& Ulrich, D. (1996). HR roles: Creating value, not rhetoric. HR Planning, 19. Retrieved July 28, 2008, from http://www.questiamedia.com/corp/site/index.html

Hagen, C. (1998). The role of human resources in whole systems change: HR as scout, chess master, cartographer, and architect. Retrieved June 28, 2008, from http://www.workinfo.com/ free/Downloads/170.htm

Hall, G. (2005). George Hall explains how Marriott attracts, retains and develops employees. In A. Warton (Ed.), People, performance, profit: Maximizing return on human capital investments, (pp. 102-103). San Francisco: Montgomery Research, Inc.

Higgins, N.J. (2005, 22 November). Measured approach to risk avoidance. Personnel Today, p. 15.

Hoepfl, M.C. (1997). Choosing qualitative research: A primer for technology education researchers, 9(1). Retrieved May 9, 2006, from http://scholar.lib.vt.edu/ejournals/JTE/v9n1/hoepfl. html

Huselid, M., Becker, B., \& Beatty, R. (2005). The workforce scorecard. Boston: Harvard Business School Press.

Kochan, T.A., \& Dyer, L. (1993). Managing transformational change: The role of human resource professionals. The International Journal of Human Resource Management, 4(3), 569-590.

Lawler, E.E., \& Mohrman, S.A. (2003). Human resources as strategic partner: What does it take to make it happen? Human Resource Planning, 26(3), 15-29.
Longbottom, D. (2005, 22 November). Numbers game only adds to confusion. Personnel Today, p. 15.

Mayo, A. (2004). Making metrics relevant. Strategic HR Review, $4(1), 7$.

McNamara, C. (1999). Overview of basic methods to collect information. Retrieved May 9, 2006, from http://www. managementhelp.org/research/overview.htm

Sanz-Valle, R., Sabater-Sanchez, R., \& Aragon-Sanchez, A. (1999). Human resource management and business strategy links: An empirical study. International Journal of Human Resource Management, 10(4), 655-671.

Saunders, M., Lewis, P., \& Thornhill, A. (2003). Research methods for business students' third edition. New York: Pearson Education Limited.

Schurink, W.J.(2004). Lectureten: Dataanalysis. Models of qualitative research. Unpublished lecture notes, Johannesburg.

Singh, P., \& Latib, M. (2005). Achieving breakthrough returns on human capital. In A. Warton (Ed.), People, performance, profit: Maximizing return on human capital investments, (pp. 160-163). San Francisco: Montgomery Research, Inc.

Sullivan, J. (2005). CEOs must expect more from their HR function. In A. Wharton (Ed.), People, performance, profit: Maximizing return on human capital investments, (pp. 148-150). San Francisco: Montgomery Research, Inc.

Terre Blanche, M., \& Durrheim, K. (1999). Research in practice. Cape Town: University of Cape Town Press.

Ulrich, D. (1998). The future calls for change. Workforce, 77(1), 87-91.

Ulrich, D., \& Brockbank, W. (2005). The HR value proposition. Boston: Harvard Business School Press.

Warton, A. (Ed.), People, performance, profit: Maximising return on human capital investments. San Francisco: Montgomery Research, Inc.

Willig, C. (2003). Introducing qualitative research in psychology. Buckingham: Open University Press.

Wright, P.M. (1992). Theoretical perspectives for strategic HR management. Journal of Management, 1992, June. Retrieved July 28, 2008, from http://findarticles.com/p/articles/ mim3495/is850/ain14933140?tag=untagged

Yin, R. (1994). Case study research: Design and methods. (2nd edn.). Beverly Hills: Sage Publishing. 